\title{
Ensuring access to consumer health information pamphlets at Capital Health
}

\author{
Penny Logan and Eleanor King
}

\begin{abstract}
Program objective - The objective of the program was to create a catalogue of patient education pamphlets and provide a stable in-house platform for the database that is sustainable with current staff resources. Rationale - Capital Health has an excellent selection of more than 1000 pamphlets specifically for patients. These pamphlets need to be accessible from the Internet, and they need to be housed on a Capital Health Web page. Main components - The main components were cataloguing the content, designing a user-friendly Web page, ensuring ongoing cataloguing is sustainable, and educating users. Setting - Capital Health, Halifax, Nova Scotia. Participants - Eleanor King, Patient Education Coordinator, Capital Health; Myrna Lawson, Library Technician; Penny Logan, Manager Library Services; Pearl Murphy, Web Coordinator; Boyd Sharpe, Systems Analyst; Deb Cameron, Graphic Designer. Program - The program was to ensure Web access to patient pamphlets. Results - 679 patient pamphlets were catalogued and presented on a user-friendly Web page in a searchable database that is controlled in-house and that can easily be kept up-to-date with current staff and systems. Conclusion - Library software and expertise can be used for more than just a catalogue of books and journals. By using already-available software and expertise, maintaining the pamphlets database can be accommodated without additional expense.
\end{abstract}

This paper does not describe the huge, time-consuming process that goes into developing patient pamphlets: the committees, the rewrites, the editing, and the creation of abstracts. That is the heavy and essential work of the Patient Education Coordinator at Capital Health. For that information, please contact Eleanor King. This paper describes how the library is involved in making sure this essential information is made available to the broadest possible publics.

Capital Health is a health district in Nova Scotia that includes 10 facilities, covers more than 2000 square miles, and serves a population of 350000 . A series of patient pamphlets has been developed that give general health information as well as specific instructions for patients, from "how to get to clinics" to "how to care for your wound at home". The 1000 patient pamphlets continue to be used in paper form, but there is increasing demand from both health professionals and the public to make these materials available on the Internet.

The electronic files for the pamphlets are created in-house and the files are housed on a Capital Health server. However, access to them has been via the Nova Scotia Health Network (NSHN) with the assistance of Dalhousie University. The NSHN-branded Web site is provided by the Dalhousie Department of Academic Computing Services. The department supervises com-

P. Logan. ${ }^{1}$ Halifax Infirmary, Room 2212, 1796 Summer Street, Halifax, NS B3H 3A7, Canada.

E. King. Patient \& Family Learning Centre, Room 4-010,

4B, Centennial, VG, 1278 Tower Road, Halifax, NS B3H 2Y9, Canada.

${ }^{1}$ Corresponding author (e-mail: penny.logan@cdha.nshealth.ca). puter science students employed on a work-term basis. The students maintain the Web page, which is hosted on a Dalhousie server. NSHN contains several links and patient information from several hospitals. To provide some subject access, a check-off template was developed by the Dalhousie Department of Medical Informatics so that an NSHN employee could easily assign each pamphlet to a category, as provided by the Patient Education Coordinator. This check-off template is displayed on the Web page and is meant to act as a search aid.

Several things happened that provided the impetus for Capital Health to take on a more active role in the process. One person at NSHN is responsible for looking after the pamphlet process, so illness or vacation meant the pamphlets were not immediately available. The NSHN Web page gives access to pamphlets from many different agencies and at differing levels of readability and quality. The Capital Health Patient Education Committee suggested in 2004 that users needed a more straightforward search page, but no action has been taken to change the search page. The biggest impetus for change was the announcement from the NSHN that it was facing some financial constraints, and there were questions about whether it would continue.

The Health Sciences Library took up the challenge to find a way to ensure the ongoing maintenance of and access to the pamphlet files. This had to be accomplished while operating within the library's current staffing and resource levels in a system that can be sustained over time and that can be maintained wholly within the resources of Capital Health should the need arise.

This project involved identifying which pamphlets will be catalogued, cataloguing the pamphlets, creating a new pa- 
Fig. 1. Patient pamphlet search page.

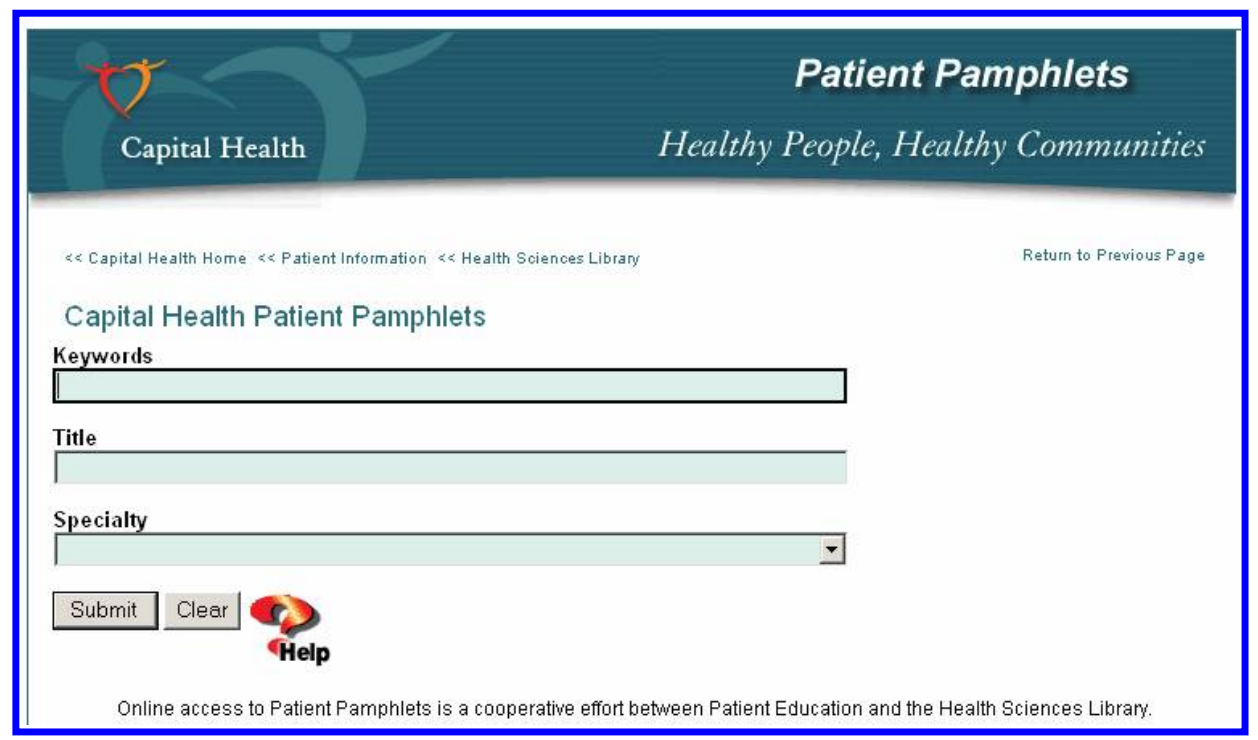

tient pamphlet Web page that is identified with Capital Health, ensuring that the new Web page is user-friendly, setting up a process so that new pamphlets can easily be incorporated into the library's cataloguing processes, and educating Capital Health staff about the new access point.

Of the 1000 pamphlets, 679 were selected for cataloguing. Those not catalogued are specialized pamphlets that require a health care professional intervention and are not meant to be publicly available. The library uses CS/TextWorks ${ }^{\circledR}$ and WebPublisher PRO (Inmagic, Inc., Woburn, Mass.) for its catalogue. This software is well known to all library staff, and thus it was straight forward to create a separate "textbase" for the patient pamphlets. The library technician worked on the project when she could find time, and the initial cataloguing was completed in May 2006. The textbase and the public Web page were modeled on the library's public catalogue so that it would take the fewest resources to implement and maintain and so that it would be familiar to our users. Because this had to be accomplished with current staffing and resources, there was an effort to catalogue at a minimum level while ensuring maximum accessibility for both Capital Health staff and the public.

The cataloguing fields we used were Title, Author, Notes, Abstract, Specialty, Language, and Year. On the public Web site the search screen has been limited to just three fields: Key words, Title, and, Specialty (Fig. 1).

Several groups were consulted (including the Patient Education Committee) to get input into how the page should look, and modifications were made to ensure that the Web page is considered user-friendly.

In addition to ensuring that there is enough white space on the page, the text in the online Help file was modified so that the language is at a level appropriate for patient education materials. And, although we enter data into the Abstract field when we catalogue, on the search results page that field is labeled "Notes".

A paper catalogue to the pamphlets has been in use for many years and is based loosely on the National Library of Medicine classification system. We wanted to show our users the same kind of list that they see in the paper catalogue.
The list is not restricted to subjects; it includes both subjects and places. We decided to put strict cataloguing rules aside in favour of showing our users a Web version of the index that is as close as possible to the paper index they use. We created a field called Specialty that shows all the classifications. It displays as a drop-down menu with the following terms: breast disease, Cancer Care Nova Scotia, cancer general, cardiovascular system, dermatology, diagnostic imaging, emergency, endocrine system, food and nutrition, gastrointestinal system, geriatrics, gynaecology, Hants Community Hospital, hematology, hospitals, infectious disease, intensive care unit, medications, musculoskeletal system, nephrology, nervous system, nursing, nursing units, ophthalmology, oral surgery, otorhinolaryngology, pain management unit, palliative care, physiotherapy, psychiatry, respiratory system, surgery, and urogenital system.

The search results appear on a screen with the following headings: Title, Year, Notes, and View. Clicking on View Pamphlet opens a PDF document displaying the full text of the pamphlet (Fig. 2).

The library worked with the Information Technology (IT) Department to find the most appropriate place within the current process for the library to be notified that a new pamphlet is available so that it can be catalogued. The IT Department has been invaluable both in its expertise and in its enthusiasm to see this project through.

There are many advantages to this arrangement:

(i) In-house expertise (no new expenditure for software)

(ii) Improved understanding by others of the capability of the library

(iii) Ability to instantly make changes to the database

(iv) Capital Health can ensure quality control

(v) Many in-house experts (no holdups because of vacation or illness)

(vi) Part of regular processes

(vii) Can make changes to accommodate what our users want (even if we have to "bend" some cataloguing rules)

The two systems continue to work in parallel. The pamphlets are still available through NSHN. The original pro- 
Fig. 2. Section of the search results page.

\begin{tabular}{|c|c|c|c|}
\hline Title & Year & Notes & View \\
\hline Angiogram & 2004 & $\begin{array}{l}\text { This pamphlet was prepared by Capital Health, Nova Scotia. During } \\
\text { this test, a colorless dye is injected into blood vessels so they can be } \\
\text { seen on x-ray. We have described getting ready for the test, what } \\
\text { happens during the test and the care after the text. Problems that need } \\
\text { immediate medical attention are given. }\end{array}$ & $\underline{\text { View Pamphlet }}$ \\
\hline Barium enema & 2006 & $\begin{array}{l}\text { This pamphlet was prepared by Capital Health, Nova Scotia. We have } \\
\text { described getting ready for this test and what happens during the test. } \\
\text { It is very important to follow the instruction you are given to prepare } \\
\text { for this x-ray. The test is like an enema except barium is used to show } \\
\text { the bowel under x-ray. The radiologist controls the barium. The } \\
\text { patient is asked to turn from side to side as films are taken. }\end{array}$ & View Pamphlet \\
\hline Bone scan & 2006 & $\begin{array}{l}\text { This pamphlet was prepared by Capital Health, Nova Scotia. A bone } \\
\text { scan is done in the Nuclear Medicine Department. A radioactive } \\
\text { material is given. Pictures are then taken with a gamma camera. The } \\
\text { dosage of the radioactive material is so small that it will not harm you. } \\
\text { If you are unable to keep your appointment, please call immediately } \\
\text { so that another patient can be booked. }\end{array}$ & View Pamphlet \\
\hline
\end{tabular}

Fig. 3. Link to the French language page.

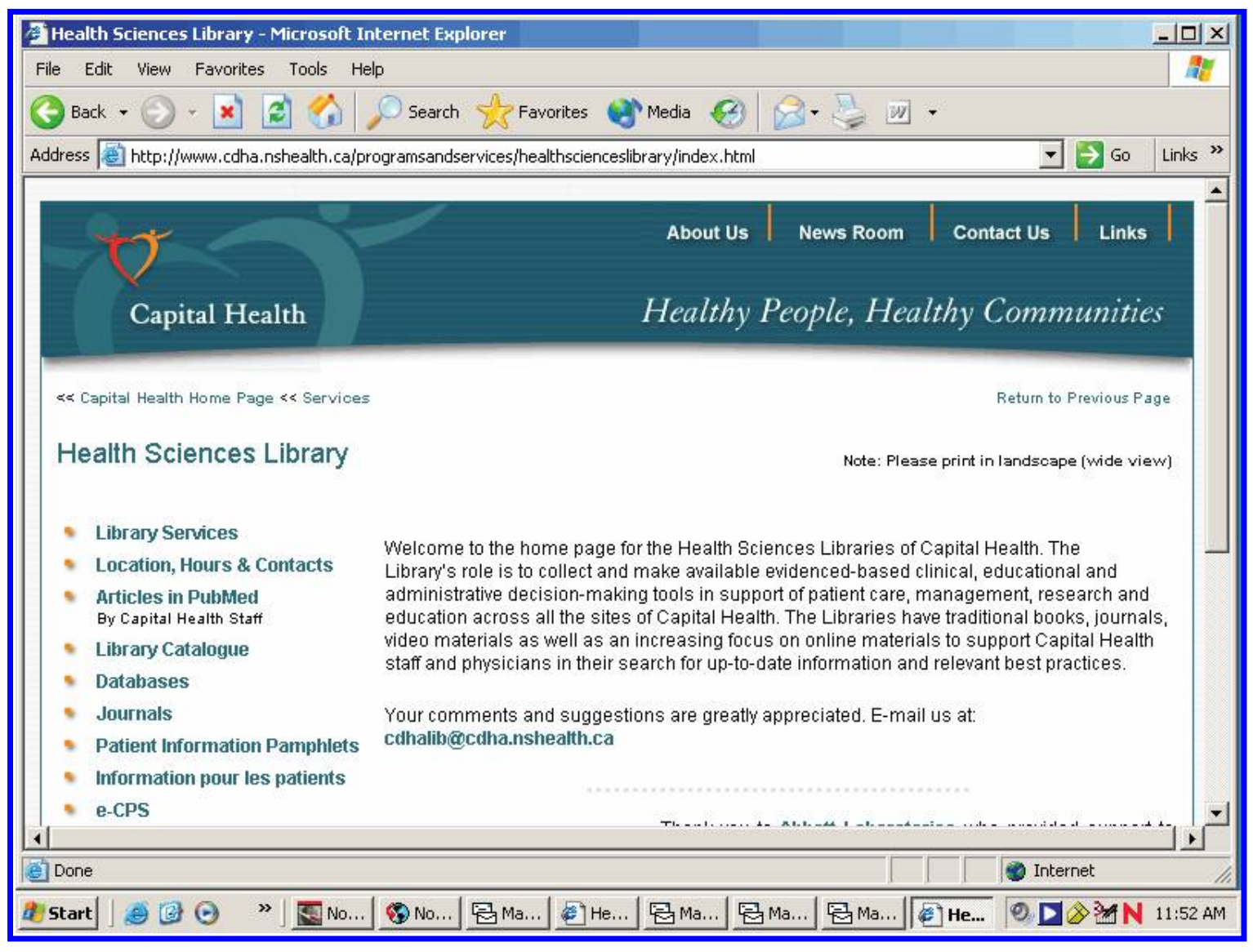


cess remains with the addition of alerting the library when a pamphlet is uploaded to the server.

Over the summer of 2006, some of the patient pamphlets were translated into French. Because we have knowledge of the software, it was very easy for library staff to add them to the catalogue along with a Language field. This both allows people to search by language and allows for future capacity because we can accommodate any number of languages.

Several training sessions have been given to Capital Health staff, and in regular library training, special mention is made of the link to the Patient Education Pamphlets Web page that appears on the main menu of the library's home page. A separate link to "Information pour les patients" directs users to the French language page (Fig. 3).

Our IT systems do not allow us at this time to measure how much traffic we get on the patient pamphlets page, but as our systems are improved, we will be looking at that statistic as an outcome that can be measured year over year.

This has been a great cooperative effort with the result that the library has increased its role in the Capital Health information processes, we have extended our contacts through the Patient Education Committee and the IT department, and we have ensured the continued access to these essential patient education materials. 